\title{
Predictive Analysis of the Damage to Axial-Flow Pump's Impeller in Sandy Water
}

\author{
Hua HONG*, Zhang ZHI-ZHONG**, Liu XIAO-BING***, Zeng YONG-ZHONG****, \\ Wang HUI-YAN***** \\ *State Key Laboratory of Hydraulics and Mountain River Engineering, Sichuan University, Chengdu 610065, Peoples R \\ China, Key Laboratory of Fluid and Power Machinery (Xihua University), Ministry of Education, Chengdu 610039, Peo- \\ ples R China, E-mail: huahong126@163.com \\ **Guodian Dadu River Zhentouba Power Generation Co. LTD, Leshan, Peoples R China, E-mail: 653452406@qq.com \\ ***Key Laboratory of Fluid and Power Machinery (Xihua University), Ministry of Education, Chengdu 610039, Peoples \\ RChina,E-mail: liuxb@mail.xhu.edu.cn \\ ****Key Laboratory of Fluid and Power Machinery (Xihua University), Ministry of Education, Chengdu 610039, Peoples \\ R China, E-mail: zyzzyzhome@163.com \\ *****Key Laboratory of Fluid and Power Machinery (Xihua University), Ministry of Education, Chengdu 610039, Peo- \\ ples R China,E-mail:191758344@qq.com
}

cross'ref http://dx.doi.org/10.5755/j01.mech.24.3.13854

\section{Introduction}

Axial flow pump is a low head and high flow pump, whose simple structure is available for urban water supply, agricultural irrigation and water diversion projects [1-2]. In recent years, the ecological and environmental conditions are worsening, soil erosion is serious, and the sediment content in most rivers is higher and higher. At present, the designs of the axial flow pump impeller are mostly based on the premise of clean water medium, which leads to the serious damage of the impeller in the actual operation, reduces the operating efficiency of pumps and increases their energy consumption. This issue has attracted great attention from scholars, and has been studied theoretically and experimentally. Some results were obtained [1-17].

Based on the Euler method, the 3D turbulence flow in the axial-flow pump impeller was numerically simulated by using the ANSYS-FLUENT, Eulerian multiphase flow model. The flow characteristics of solid-liquid two-phase flow were studied, and the results were compared with those in clear water.

\section{Equations}

The following assumptions have been made in this study:

1. The liquid phase (water) is incompressible. The solid phase (sand) is continuous. The physical properties of each phase are constants.

2. The solid phase consists of sand particles spherical in shape and uniform in size.

3. Neither the suspended matter nor the carrier liquid undergoes any phase change.

4. Interactions between particles, as well as between particles and the wall are neglected.

\subsection{Basic equations of solid-liquid two-phase flow}

The motion equations of solid-liquid two-phase flow in the Eulerian coordinate system are as follows [2]:

Liquid phase continuity equation:

$$
\frac{\partial \phi_{L}}{\partial t}+\frac{\partial}{\partial x_{i}}\left(\phi_{L} U_{i}\right)=0
$$

Solid phase continuity equation:

$$
\frac{\partial \phi_{S}}{\partial t}+\frac{\partial}{\partial x_{i}}\left(\phi_{S} V_{i}\right)=0
$$

Liquid phase momentum equation:

$$
\begin{aligned}
& \frac{\partial}{\partial x_{i}}\left(\phi_{L} U_{i}\right)+\frac{\partial}{\partial x_{k}}\left(\phi_{L} U_{i} U_{k}\right)=-\frac{1}{\rho_{L}} \phi_{L} \frac{\partial P}{\partial x_{i}}+ \\
& +v_{L} \frac{\partial}{\partial x_{i}}\left[\phi_{L}\left(\frac{\partial U_{i}}{\partial x_{k}}+\frac{\partial U_{k}}{\partial x_{i}}\right)\right]-\frac{B}{\rho_{i}} \phi_{L} \phi_{S}\left(U_{i}-V_{i}\right)+\phi_{L} g_{i} .
\end{aligned}
$$

Solid phase momentum equation:

$$
\begin{aligned}
& \frac{\partial}{\partial t}\left(\phi_{S} V_{i}\right)+\frac{\partial}{\partial x_{k}}\left(\phi_{S} V_{i} V_{k}\right)=-\frac{1}{\rho_{S}} \phi_{S} \frac{\partial P}{\partial x_{i}}+ \\
& +v_{s} \frac{\partial}{\partial x_{k}}\left[\phi_{S}\left(\frac{\partial V_{i}}{\partial x_{k}}+\frac{\partial V_{k}}{\partial x_{i}}\right)\right]-\frac{B}{\rho_{S}} \phi_{L} \phi_{S}\left(V_{i}-U_{i}\right)+\phi_{S} g_{i} .
\end{aligned}
$$

Where: $U_{i}$ and $V_{i}$ are respectively the velocity components of the liquid and solid phase; $\rho$ is the material density of phases; $v$ is the kinematic viscosity coefficient; $P$ reprensents the gravity acceleration component; $g$ is the component of gravity acceleration; and $x_{i}$ is the coordinate component. The equation of $B=18\left(1+B_{0}\right) \rho_{L} v_{L} / d^{2}$ indicates the interaction coefficient between phases, in which $d$ is the particle diameter. And the introduction of $B_{0}$ in it is to consider other factors besides the stokes linear resistance. Generally speaking, $B_{0}$ is not a constant, for it is related to the flow field parameters such as the particle Reynolds number. $\phi$ is a phase volume number with the relation equation of $\phi_{L}+\phi_{S}=1$, in which the subscripts $L$ and $S$ represent the liquid and solid phases, respectively, while $i$ and $k$ are the tensor coordinates. 
2.2. Turbulence calculation model

The RNG $k-\varepsilon$ model [2] was used in this study, which can be written as:

$$
\begin{aligned}
& \frac{\partial}{\partial t}(\rho k)+\frac{\partial}{\partial x_{i}}\left(\rho k u_{i}\right)=\frac{\partial}{\partial x_{j}}\left[\left(\mu+\frac{\mu_{t}}{\sigma_{k}}\right) \frac{\partial k}{\partial x_{j}}\right]+G_{k}+G_{b}-\rho \varepsilon-Y_{M}+S_{k} . \\
& \frac{\partial}{\partial t}(\rho \varepsilon)+\frac{\partial}{\partial x_{i}}\left(\rho \varepsilon u_{i}\right)=\frac{\partial}{\partial x_{i}}\left[\left(\mu+\frac{\mu_{t}}{\sigma_{\varepsilon}}\right) \frac{\partial \varepsilon}{\partial x_{j}}\right]+C_{1 \varepsilon} \frac{\varepsilon}{k}\left(G_{k}+C_{3 \varepsilon} G_{b}\right)-C_{2 \varepsilon} \rho \frac{\varepsilon^{2}}{k}+\mathrm{S}_{\varepsilon} .
\end{aligned}
$$

Where: $G_{k}$ is the turbulent kinetic energy caused by the average velocity gradient; $G_{b}$ represents the turbulent kinetic energy caused by buoyancy influence; $Y_{M}$ represents the influence of the total dissipation rate by the compressible turbulence fluctuation expansion; $\alpha_{k}$ and $\alpha_{g}$ are the reciprocals of effective turbulent Prandtl numbers of the turbulent kinetic energy $k$ and dissipation rate $\varepsilon$. The calculation formula of turbulent viscosity coefficient is:

$$
d\left(\frac{\rho^{2} k}{\sqrt{s \mu}}\right)=1.72 \frac{v}{\sqrt{v^{3}-1-C_{v}}} d v
$$

where: $v=\mu_{\text {eff }} / \mu$, and $C_{v}=100$. And in Fluent, $C_{l \varepsilon}=1.44$, $C_{2 \varepsilon}=1.92, C_{3 \varepsilon}=0.09$ are all default constants.

\section{Calculation parameters}

\subsection{Basic parameters of pump}

The basic parameters of the pump are listed in Table 1.

Table 1

Basic design parameters of the pump

\begin{tabular}{|c|c|c|}
\hline Name & Unit & Parameters \\
\hline Pump type & & axial-flow \\
\hline Blade number $(Z)$ & PCS & 4 \\
\hline Head $(H)$ & $\mathrm{m}$ & 2.5 \\
\hline Flow rate $(Q)$ & $\mathrm{m}^{3} / \mathrm{h}$ & 12500 \\
\hline Speed $(n)$ & $\mathrm{r} / \mathrm{min}$ & 235 \\
\hline
\end{tabular}

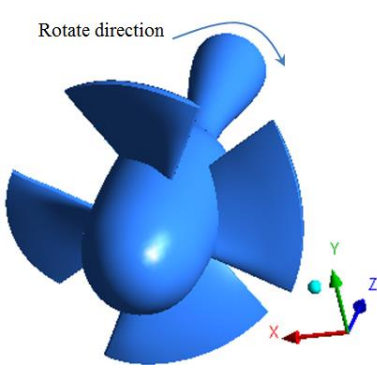

a

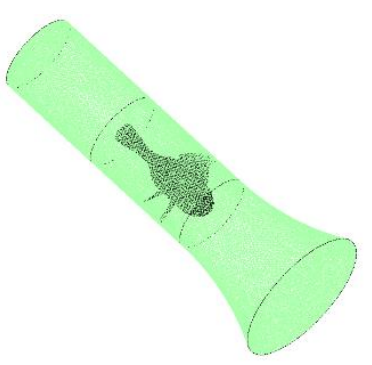

$\mathrm{b}$
Fig. 1 3D model of the axial-flow pump impeller and grids: $a-3 D$ model of the axial flow impeller; $b$ - flow passage meshing

The entire flow passage consists of three parts, the tapered inlet stationary part, the impeller rotation part and the outlet stationary part. The 3D model of the axial-flow pump impeller is shown in the Fig. 1, a, and the direction of impeller rotation is forward along the Z-Axis. The entire flow passage was divided by unstructured grids, and the results are shown in the Fig. 1, b. The number of grids is 910,000 .

\subsection{Boundary conditions}

The velocity inlet was used, and it was assumed that the inlet has uniform incoming flow, and the inlet velocity was vertical to the inlet boundary surface. The outlet was provided with flow outlet with the conditions of free development, that is to say, except the outlet pressure, the positive normal gradients of all flow variables were assumed as zero. The velocity on the solid wall can meet with the no-slip wall conditions, and the standard wall function was adopted for the near wall area. The average diameter of solid particles was $0.2 \mathrm{~mm}$, and the density of solid phase material (sand in this study) was $2,719 \mathrm{~kg} / \mathrm{m}^{3}$. The impact of gravity to the flow field during the calculation was considered and the direction of gravity was reverse to the normal of the pump outlet section.

\subsection{Calculation conditions}

The turbulent flow in an axial flow impeller was numerically simulated in the clear water (single-phase flow) and the sandy water (solid-liquid two-phase flow) conditions. According to the statistical data of the content of river sediment, three sediment concentrations were selected. The sand volume concentrations (fractions) of various conditions are listed in Table 2.

Table 2

Statistics of CFD calculation conditions

\begin{tabular}{|c|c|c|}
\hline No. & Quality of water & $\begin{array}{c}\text { Volume concentration of } \\
\text { sand }\end{array}$ \\
\hline condition1 & clear water & 0 \\
\hline condition2 & sandy water & $0.38 \%$ \\
\hline condition3 & sandy water & $0.76 \%$ \\
\hline condition4 & sandy water & $1 \%$ \\
\hline
\end{tabular}

\section{Calculation results and analysis}

With the use of RNG $k-\varepsilon$ turbulence model, SIMPLEC algorithm and CFD software, the turbulent flow in an axial flow impeller was numerically simulated in the clear water (single-phase) and the sandy water (solid-liquid twophase) conditions. The distributions of solid concentration, velocity and pressure on the impeller of the axial flow pump were analyzed at the various conditions.

\subsection{Static pressure distribution}

Figs. 2-5 show the static pressure distributions on 
the leading side and the suction side of the blade in various conditions (including clear water and sandy water). In general, the pressure on the leading side is larger than that on the suction side. The pressure on the leading side of the blade is changing along the radius direction, and there is a small high pressure zone near the outlet flange and a small low pressure zone near the inlet flange. The pressure on the suction side is mainly changing in the circumferential direction, which reduces and then increases from the inlet to the outlet. There is a small high pressure zone near the outlet flange and a small low pressure zone near the inlet flange on the suction side. The minimum pressure on the blade is on the suction side near the inlet, which is the part most vulnerable to cavitation on the impeller.

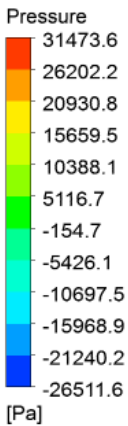

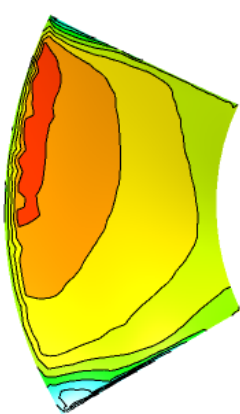

a
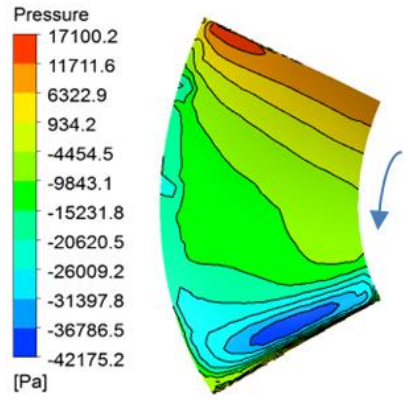

b
Fig. 2 Pressure distribution on blades in condition 1 (clear water): $a$ - leading side; $b$ - suction side
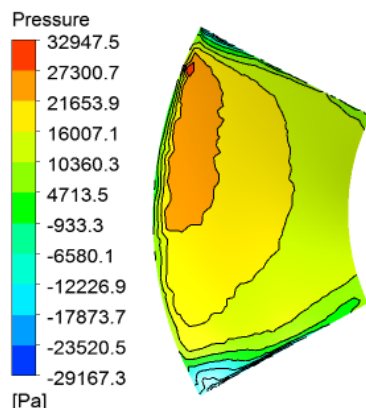
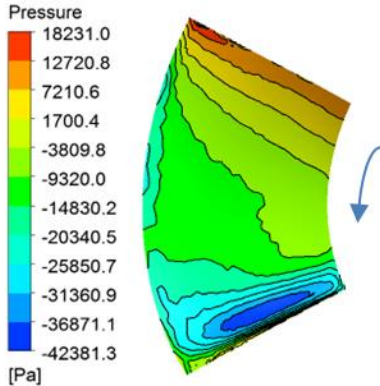

b
Fig. 3 Pressure distribution on blades in condition 2 (sediment concentration of $0.38 \%$ ): a - leading side; $\mathrm{b}$ - suction side

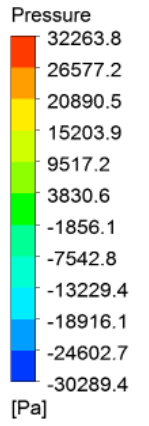

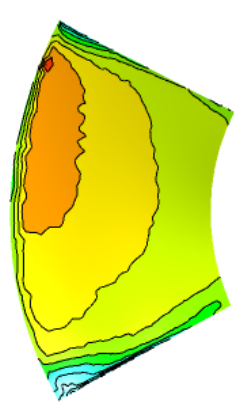
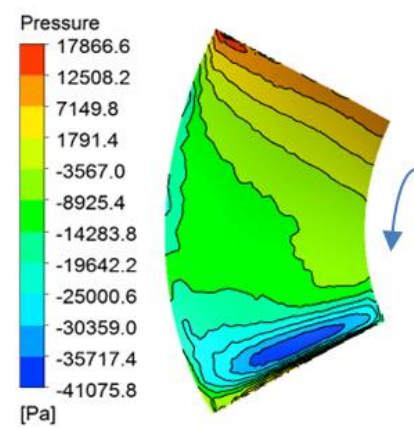

b
Fig. 4 Pressure distribution on blades in condition 3 (sediment concentration of $0.76 \%$ ): a - leading side; b - suction side

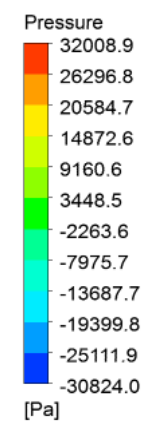

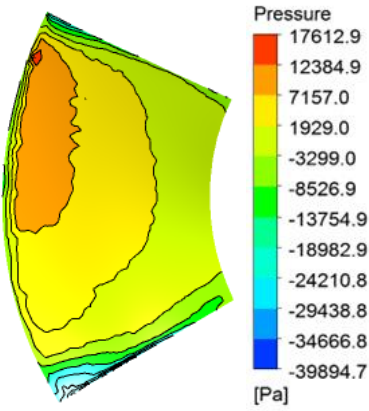

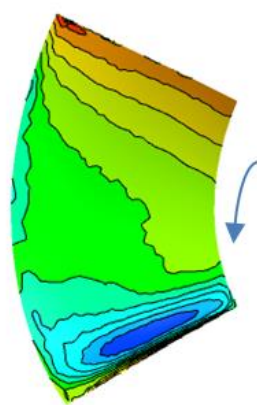

b
Fig. 5 Pressure distribution on blades in condition 4 (sediment concentration of 1\%): a - leading side; b - suction side

The minimum pressure in solid-liquid two-phase flow is lower than that in single-phase flow, which is shown in Fig. 6. The impeller is more vulnerable to cavitation in solid-liquid two-phase flow than that in single-phase flow. So the axial pump impeller will be damaged more easily and quickly in sandy water than in clear water.

With the increasing of the solid phase volume concentration in solid-liquid two-phase flow, the pressure gradually reduces. This indicates that in the solid-liquid twophase flow, due to the existence of the solid phase, the more the sediment content is, the more vulnerable of cavitation in the low pressure zone will be. This is consistent with the abrasion of impeller in practical projects.

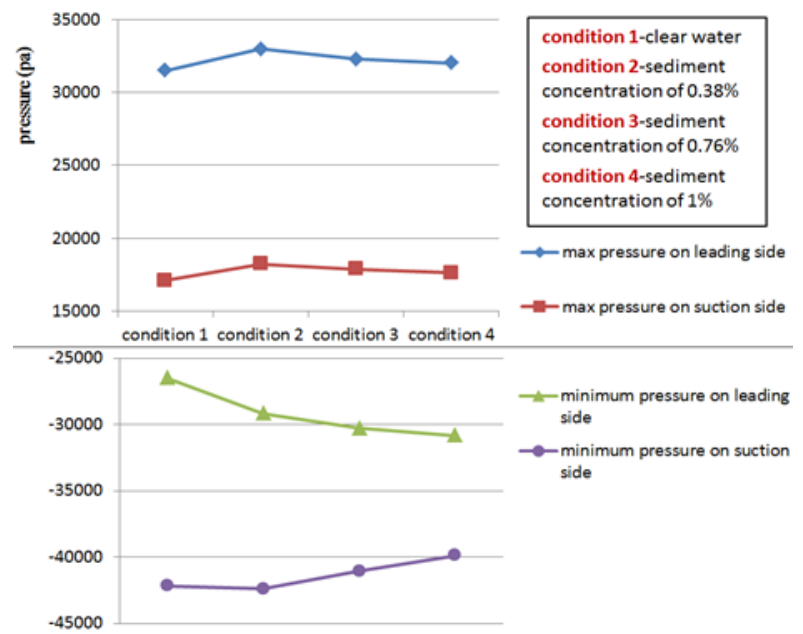

Fig. 6 Max and minimum pressure in various conditions

4.2. Volume concentration distribution of solid phase particles

Figs. 7-9 show the volume concentration distributions of solid phase particles on the leading side and the suction side of blades in sandy water (solid-liquid two-phase flow) with various sediment concentrations. It shows that the distribution laws on the leading side and the suction side are different. In general, the solid phase concentration on the leading side of the blade is larger than that on the suction side. The solid phase concentration at the inlet edge is relatively higher on the leading side and the suction side. The abrasion on the part with higher solid phase concentration is serious, which is consistent with practical projects. There is a low concentration zone of solid phase on the leading side 
near the inlet and the flange, which is formed by the impact on the inlet wall as the pop-up of the solid phase particles with certain angle.

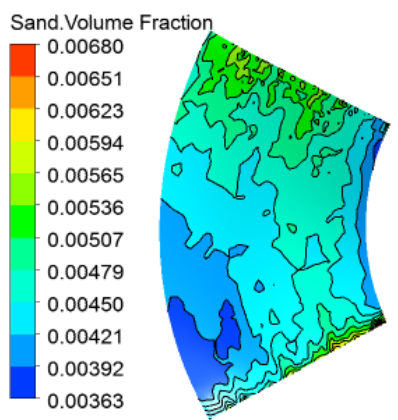

a

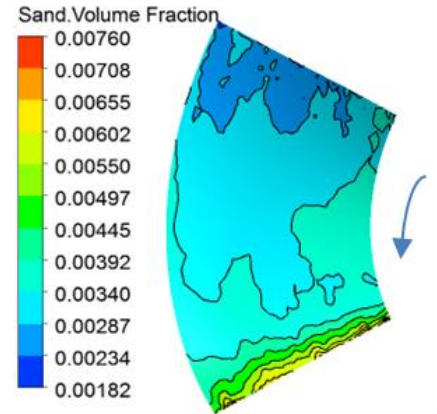

b
Fig. 7 Pressure distribution on blades in condition 2 (sediment concentration of $0.38 \%$ ): a-leading side; b - suction side

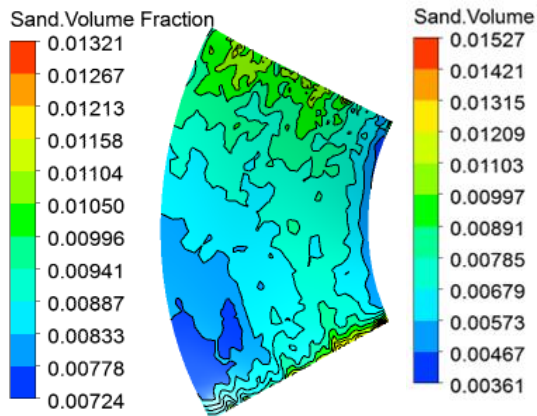

a

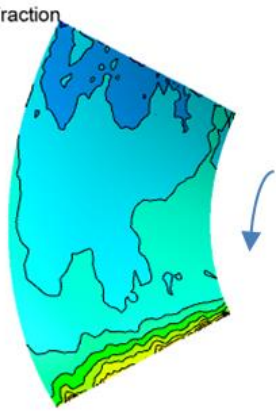

b
Fig. 8 Pressure distribution on blades in condition 3 (sediment concentration of $0.76 \%$ ): a-leading side; b - suction side

Sand.Volume Fracti
\begin{tabular}{|l}
0.01714 \\
0.01644 \\
0.01575 \\
0.01506 \\
0.01437 \\
0.01367 \\
0.01298 \\
0.01229 \\
0.01160 \\
0.01090 \\
0.01021 \\
0.00952
\end{tabular}

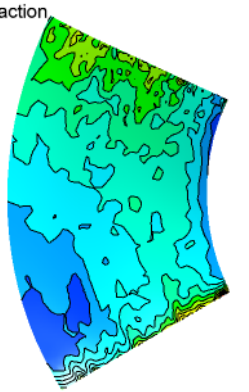

a

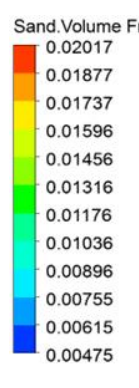

b
Fig. 9 Pressure distribution on blades in condition 4 (sediment concentration of $1 \%$ ): $a$ - leading side; $b$ - suction side

The higher the solid phase volume concentration is, the higher the solid phase concentration on the blade surface will be, which is shown in Fig. 10. The higher the sediment concentration, the higher is the solid phase volume concentration near the blade surface, and the more serious of abrasion.

Under the combined effects of sand abrasion and cavitation, the extent of damage to the blades greatly intensified. This is consistent with the actual engineering situation. In the hydraulic design of this type of pump, some improvement measures should be taken to reduce the damage as much as possible.

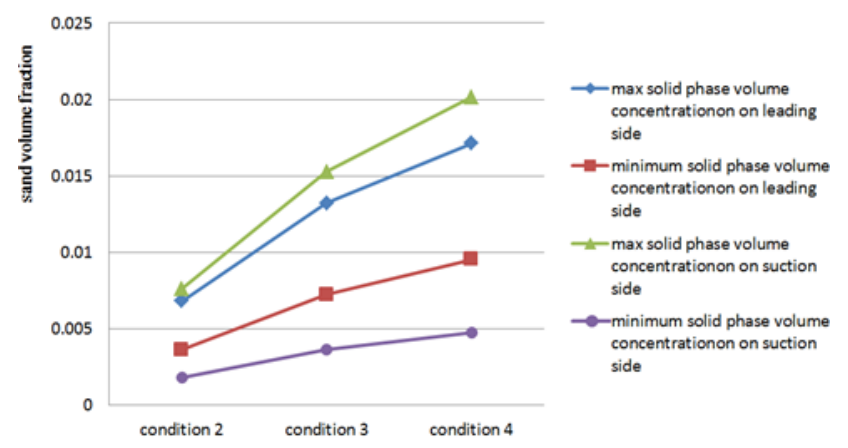

Fig. 10 Max and minimum Solid phase volume concentration in various conditions

\subsection{Velocity distribution}

Figs. 11-14 show the distributions of relative velocity of the liquid phase (water) near the surface of the axial-flow pump blades (hereinafter referred to as blade surface). The figures show that the relative velocity near the blade surface is gradually increasing in radial direction from the hub to the flange. The relative velocity at the suction side is larger than that at the leading side. The relative velocity gradually decreases from the inlet to the outlet at the leading side and suction side. The relative velocity of the liquid phase in the solid-liquid two-phase flow is smaller than that in single-phase flow. This is caused by the solid phase which hinders the velocity of the liquid phase. Furthermore, with the increasing of sediment content, the velocity in the impeller reduces.

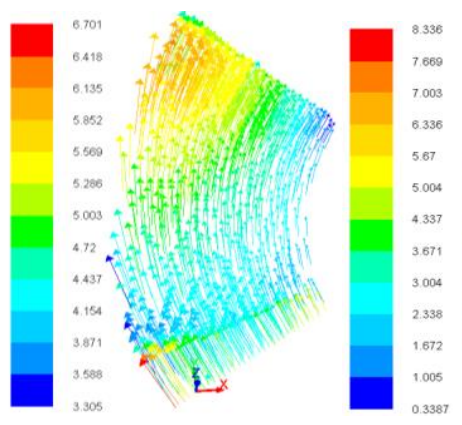

a

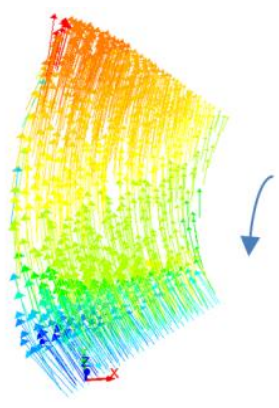

b
Fig. 11 Liquid phase relative velocity distribution near blades in condition 1 (clear water) : a - leading side; b - suction side

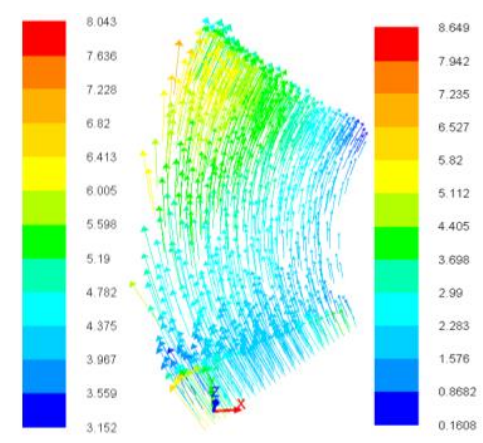

a

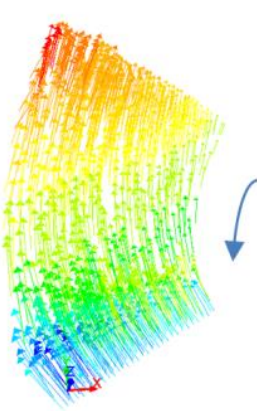

b
Fig. 12 Liquid phase relative velocity distribution near blades in condition 2 (sediment concentration of $0.38 \%$ ): a - leading side; $\mathrm{b}$ - suction side 


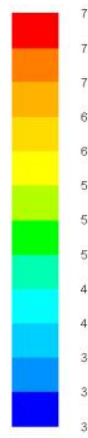

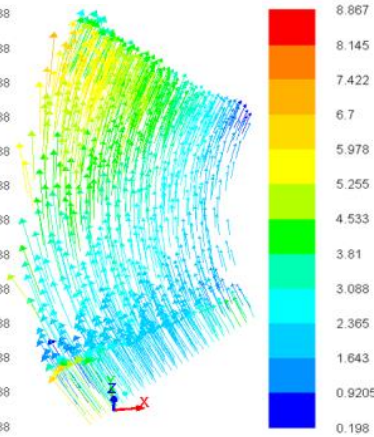

a

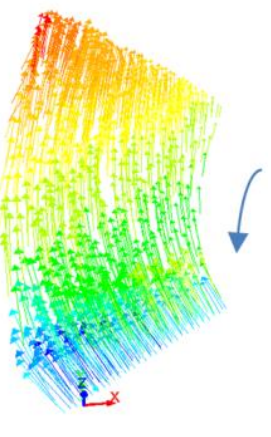

b
Fig. 13 Liquid phase relative velocity distribution near blades in condition 3 (sediment concentration of $0.76 \%$ ): a - leading side; $\mathrm{b}$ - suction side

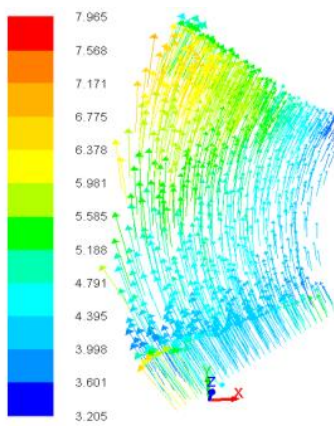

a
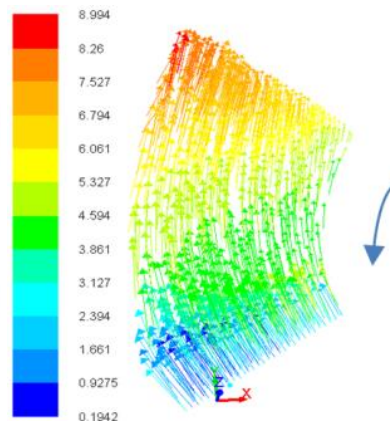

b
Fig. 14 Liquid phase relative velocity distribution near blades in condition 4 (sediment concentration of $1 \%$ ): $a$ - leading side; $b$ - suction side

\section{Conclusions}

According to the simulation results, the pressure, velocity and the distributions of solid concentration on the impeller of an axial flow pump in different conditions are compared and analyzed. The following conclusions are obtained:

1. According to the simulation results, the axial pump impeller will be damaged more easily and quickly in sandy water than in clear water.

2. The area most prone to damage on the axial flow impeller is predicated, which is near the inlet edge on the leading side and the suction side of blades. Due to the minimum pressure on the blade near the inlet, the solid phase concentration at the inlet edge is relatively higher. Under the combined effects of sand abrasion and cavitation, the extent of damage to the blades is greatly intensified.

3. This study shows that the numerical simulation results are the same as the actual situation, and it has guiding significance for the wear design of the axial flow pump. In the hydraulic design of this type of pump, some improvement measures should be taken to reduce the damage as much as possible.

\section{Acknowledgments}

The work described in this paper is supported by the National Key Research and Development Program "Research and Application Demonstration of Complementary Combined Power Generation Technology between Distributed Photovoltaic and Cascade Small Hydropower" (Grant
No.2018YFB0905200), the National Natural Science Foundation of China (Grant No. 51279172), the Fundamental Research Funds for the Central Universities (Grant No. 2012017yjsy169) and the Open Research Fund of the Key Laboratory of Fluid and Power Machinery, Ministry of Education (Xihua University) (Grant No. szjj2017-087).

\section{References}

1. Roco, M. C.; Reinhart, E. 1980. Caculation of solid particles concentration in centrifugal pump impellers by using finite element technique, Hydro Transport 7: 359370 .

2. Liu Xiaobing. 1996. Solid-liquid two-phase flow and numerical simulation in turbo machinery, China Water Conservancy and Hydropower Press, Beijing, China.

3. Liu Xiaobing; Zhang Jiachuan; Cheng Liangjun. 1998. Numerical Simulation of Sand Particle Motion in Rotating Field, Journal of Hydrodynamics, Ser. A 13 (3): 338-346.

4. Liu Xiaobing. 2000. Numerical simulation of sediment abrasion in hydraulic machinery, Sichuan Univ Sci Technol 19(2): 79-84.

5. S. C. Li. Carpenter. 2002. Anti erosion turbine: cavitation \& silt synergetic erosion, The 9th International Symposium on Transport Phenomena and Dynamics of Rotating Machinery, Honolulu, Hawaii:10-14.

6. Yuan, Shouqi; Zhang, Peifang; Zhang, Jinfeng; Xu, Weixing. 2004. Numerical simulation of 3-d dense solid-liquid two-phase turbulent flow in a non-clogging mud pump, Chinese Journal of Mechanical Engineering (English Edition) 17(4): 623-627.

https://www.engineeringvillage.com/search/doc/detailed.url?SEARCHID=b94dce1cM69e8M48a4M97de M6d592c6ee427\&DOCINDEX=1\&database $=1 \&$ page Type $=$ quickSearch $\&$ searchtype $=$ Quick \&dedupResultCount=null\&format=quickSearchDetailedFormat\&usageOrigin=recordpage $\&$ usageZone $=$ abstracttab $\&$ toolsinScopus=Noload. https://doi.org/10.3901/CJME.2004.04.623.

7. Liu, Shuhong; Tang, Xuelin; Wu, Yulin; Nishi, Michihiro. 2004. Simulation of dense solid-liquid two-phase flow in a pump impeller, The ASME Heat Transfer/Fluids Engineering Summer Conference 2004, HT/FED (2) A: 461-467.

https://www.engineeringvillage.com/search/doc/abstract.url?\&pageType=quickSearch\&usageZone=resultslist\&usageOrigin=searchresults\&searchtype $=$ Quick \&SEARCHID=310067d5M09c5M41a5M9 dc9Mb8dcce53ec44\&DOCINDEX=1\&ignore_docid=cpx_4f1d0d1054e841411M732f19255120119\&database $=1 \&$ format $=$ quickSearchAbstractFormat\&tagscope $=\&$ displayPagination $=$ yes .

8. Keck, H.; Dekumbis, R.; Sick, M. 2005. Sediment erosion in hydraulic turbine and experiences with advanced coating technologies, In: India Hydro 2005; International workshop and conference.

9. Park, Jong-Myung; Yoon, Chi-Ho; Park, YongChan; Kim, Young-Ju; Lee, Dong-Kil; Kwon, SeokKi, 2007. Three dimensional solid-liquid flow analysis for design of two-stage lifting pump, Proceedings of the ISOPE Ocean Mining Symposium, pp. 171-176. 
https://www.engineeringvillage.com/search/doc/abstrac t.url? \&pageType=quickSearch\&usageZone=resultslist \&usageOrigin $=$ searchresults\&searchtype $=$ Quick \&SEA RCHID=9965fb91M3904M4a52MbfeaM07d6f1c7519 d\&DOCINDEX=1\&ignore_docid=cpx_30c221115a48 0354aM74e32061377553\&database $=1 \&$ format $=$ quickS earchAbstractFormat\&tagscope $=\&$ displayPagination $=y$ es.

10. Pagalthivarthi, Krishnan V.; Visintainer, Robert J. 2009. Solid-liquid flow-induced erosion prediction in three-dimensional pump casing. The ASME Fluids Engineering Division Summer Conference 2009, FEDSM2009 1(PART A): 611-617. https://dx.doi.org/10.1115/FEDSM2009-78274.

11. Haiku, Zhang; Liu, Xiaobing; He, Ting; et al. 2009. Three-dimensional performance prediction of whole flow passage of Francis turbine operating in Sandy River, Water Resour Power; 27(2): 158-160.

12. Eltvik, M.; Neopane, H.P.; Dhalhaug, O.G. 2011. Prediction of sediment erosion in Francis turbines, In: Proceedings of 4-th international meeting on cavitation and dynamic problems in hydraulic machinery and Systems, Serbia.

13. Thapa, B.; Thapa, B.S.; Dahlhaug, O.G.; Shrestha, K.P. 2012. Accelerated testing for resistance to sand erosion in hydraulic turbines, In:Fourth International Conference on Water Resources and Renewable Energy Development in Asia, Thailand, March, p.p. 26-27.

14. Peng, Guangjie; Wang, Zhengwei; Xiao, Yexiang; Luo, Yongyao. 2013. Abrasion predictions for Francis turbines based on liquid-solid two-phase fluid simulations, J. Engineering Failure Analysis (33): 327-335. https://ac.els-cdn.com/S1350630713002021/1-s2.0S1350630713002021-main.pdf?_tid=e2637ffc-b6734d87-8605cd9ef2f45bc0\&acdnat $=1524621972 \_48 f 2 b a c 2 e 5 b f 601$ e19d8618ba24b3723.

15. Baocheng, Shi; Jinjia, Wei. 2014. Numerical Simulation of 3D Solid-Liquid Turbulent Flow in a Low Specific Speed Centrifugal Pump: Flow Field Analysis, J. Advances in Mechanical Engineering ID 814108, p.p. 11.

http://journals.sagepub.com/doi/pdf/10.1155/2014/8141 08 .

16. Hua, Hong; Zeng, Yong-Zhong; Wang, Hui-Yan; Ou, Shun-Bing; Zhang, Zhi-Zhong; Liu, Xiao-Bing. 2015. Numerical analysis of solid-liquid two-phase turbulent flow in Francis turbine runner with splitter blades in sandy water, J. Advances in Mechanical Engineering 7(3):1-10.

http://journals.sagepub.com/doi/pdf/10.1177/16878140 15573821.

17. Demin, Liu; Xiaobing, Liu; Yongzhi, Zhao. 2017. Experimental Investigation of Inter-Blade Vortices in a Model Francis Turbine, J. Chinese Journal of Mechanical Engineering 30(4):854-865.

https://link.springer.com/article/10.1007\%2Fs10033017-0097-1.

https://doi.org/10.1007/s10033-017-0097-1.

Hua Hong, Zhang Zhi-Zhong, Liu Xiao-Bing, Zeng YongZhong, Wang Hui-Yan PREDICTIVE ANALYSIS OF THE DAMAGE TO AX-
IAL-FLOW PUMP'S IMPELLER IN SANDY WATER

S u m m a r y

With the use of RNG k- $\varepsilon$ turbulence model, SIMPLEC algorithm and CFD software, the turbulent flow in an axial flow impeller was numerically simulated in the clear water (single-phase) and the sandy water (solid-liquid twophase) conditions. The distributions of solid concentration, velocity and pressure on the impeller of an axial flow pump were analyzed at the same particle diameter but different volume concentrations in sandy water. And these distributions were comparatively analyzed under the clear water and the sandy water conditions. According to the simulation results, the axial pump impeller will be damaged more easily and quickly in sandy water than in clear water. And the area more prone to damage on the axial flow impeller is predicated. The predicted vulnerable parts in an axial flow impeller are consistent with that in actual projects. This study shows that the numerical simulation results are the same as the actual situation, and it has guiding significance for the wear design of the axial flow pump.

Keywords: axial-flow pump; impeller; solid-liquid twoPhased; CFD numerical simulation; prediction analysis.

Received December 12, 2015 Accepted June 14, 2018 